\title{
Tratamento cirúrgico-ortodôntico do dente 33: relato de caso clínico
}

\author{
Surgical-orthodontic treatment of the tooth 33: case report \\ Cirugía y ortodoncia dental tratamiento 33: reporte de caso \\ Vanessa Cristina da Silva MARCELINO ${ }^{1}$ \\ Marlene Cabral Coimbra da $\mathbf{C R U Z}^{2}$ \\ André Luís da Silva FABRIS ${ }^{3}$ \\ Mariângela Borghi Ingraci DE LÚCIA ${ }^{3}$ \\ Lucieni Cristina Trovati MORETI ${ }^{4}$ \\ Karina Gonzales Câmara FERNANDES ${ }^{4}$ \\ ${ }^{1}$ Graduanda do Curso de Odontologia da Universidade Brasil, 15600-000 Fernandópolis - SP, Brasil. \\ ${ }^{2}$ Professora das Disciplinas de Saúde Coletiva e Imaginologia do Curso de Odontologia da Universidade Brasil, \\ 15600-000 Fernandópolis - SP, Brasil. \\ ${ }^{3}$ Professor(a) da Disciplina de Cirurgia do Curso de Odontologia da Universidade Brasil, \\ 15600-000 Fernandópolis - SP, Brasil. \\ ${ }^{4}$ Professora das Disciplinas de Endodontia e Clinicas Integradas do Curso de Odontologia da Universidade Brasil, \\ 15600-000 Fernandópolis - SP, Brasil.
}

\begin{abstract}
Resumo
A erupção dentária é um processo fisiológico que consiste no trajeto realizado pelo germe dentário até atingir seu plano funcional na cavidade oral, porém tal processo pode sofrer alterações provocando sua falha ou interrupção. A impacção é uma dessas alteraç̃oes, onde o dente permanece retido sob dentes adjacentes, tecido ósseo ou tecido mole, sendo os caninos um dos dentes que mais sofrem impacções. Retenção ou perda precoce do decíduo, presença de odontoma e espaços disponíveis no arco, são algumas possíveis causas das impacções caninas. O propósito deste trabalho foi relatar um caso clínico de tratamento cirúrgico-ortodôntico de canino impactado pela presença de dente decíduo e odontoma. Paciente foi referenciado à Universidade Brasil por seu ortodontista com solicitação de procedimento cirúrgico de remoção do odontoma e colagem de botão para tracionamento do dente 33 impactado. Em radiografia panorâmica apresentada, o dente decíduo (dente 73) já havia sido removido, mas ainda havia a presença do odontoma no local. O tratamento cirúrgico foi realizado com enucleação da lesão e o dente preparado para o tracionamento ortodôntico, com colagem de botão ortodôntico. Conclui-se que o caso relatado apresentou um diagnóstico precoce e prognóstico favorável, o que tornou possível o estabelecimento da estética e função. Descritores: Dente Impactado; Odontoma; Tração.
\end{abstract}

\begin{abstract}
The dental eruption is a physiological process that consists in the pathway of the dental germ until reaching its functional plane in the oral cavity, but this process can change causing its failure or interruption. Impaction is one of these alterations, where the tooth remains retained under adjacent teeth, bone tissue or soft tissue, and the canines are the ones that most often suffer with impactions. Early retention or loss of the deciduous, presence of odontoma and spaces available in the arch are some possible causes of canine impactions. The purpose of this work was to report a clinical case of canine orthodontic treatment impacted by the presence of a deciduous tooth and odontoma. The patient was referred to the Universidade Brasil by the orthodontist with request of a surgical procedure of removal of the odontoma and bonding of the button for traction of the impacted tooth. In panoramic radiograph, the deciduous tooth (tooth 73) had already been removed, but there was still the presence of the odontoma in place. The surgical treatment was performed with enucleation of the lesion and the tooth prepared for orthodontic traction, with orthodontic button gluing. It is concluded that the case reported presented an early diagnosis and favorable prognosis, which made possible the establishment of a esthetics and function.
\end{abstract}

Descriptors: Tooth, Impacted; Odontoma; Traction.

\section{Resumen}

La erupción de los dientes es un proceso fisiológico que es el camino tomado por el germen del diente para lograr em su plan funcional en la cavidad oral, pero este proceso puede cambiar causando su falla o interrupción. La impactación es uno de esos cambios, donde el diente queda retenido en los dientes adyacentes, hueso o tejido blando, y los caninos de los dientes que sufren la mayoría de impactaciónes. La conservación o la pérdida temprana de la presencia de hojas caducas de odontoma y espacios disponibles en el arco son algunas de las posibles causas de impactaciónes caninas. El propósito de este estudio fue presentar un caso de tratamiento quirúrgico-ortodóncico del diente canino retenido por la presencia de hojas caducas y odontoma. El paciente fue referenciado a la Universidade Brasil por el ortodoncista para solicitar intervención quirúrgica de extirpación del odontoma y el botón de adherencia de tracción 33 dientes impactados. En la radiografía panorámica, el diente primario (diente 73) ya había sido retirado, pero sigue existiendo la presencia odontoma en el sitio. El tratamiento quirúrgico se realizó con la enucleación de la lesión y el diente preparado para la tracción de ortodoncia con ortodoncia collage botón. Se concluye que el caso clínico presentado el diagnóstico precoz y pronóstico favorable, lo que hizo posible la creación de la estética y la función.

Descriptores: Diente Impactado; Odontoma; Tración.

\section{INTRODUÇÃO}

A erupção dentária é um processo fisiológico que se identifica pelo trajeto do germe dentário dentro dos ossos maxilares até atingir o plano funcional na cavidade oral. Ocorre numa sequência e tempo já estabelecidos pela natureza mas que podem sofrer alterações provocando falha ou interrupção do mesmo ${ }^{1}$.

Resultante de erupção ectópica, a impacção dentária está presente quando determinado dente não consegue erupcionar e permanece retido sob dentes adjacentes, tecido ósseo ou tecido mole após transcorrer o seu período de erupção ${ }^{2}$.

Os dentes que mais comumente sofrem de impacção são: terceiros molares inferiores e superiores, caninos e prémolares ${ }^{2-4}$

Com relação aos caninos, os superiores sofrem de impacção com maior frequência do que os inferiores. Em 
casos mais raros ocorre bilateralmente. Possui predileção à crianças e adolescentes do sexo feminino ${ }^{3,5}$.

As causas relatadas de impacção canina são: falta de espaço disponível no arco, retenção prolongada ou perda precoce do decíduo, posição anormal do germe permanente, presença de fissura palatina, anquilose, presença de odontoma ou dentes supranumerários, formação de cistos ou neoplasias, fatores genéticos ${ }^{1,3,5-8}$.

O odontoma é o tumor odontogênico mais prevalente, considerado como uma anomalia de desenvolvimento que surge a partir da proliferação da lâmina do epitélio odontogênico. De evolução lenta, é diagnosticado nos exames radiográficos de rotina e classificado de acordo com suas características em composto ou complexo ${ }^{6,9}$.

Clinicamente, o odontoma composto é formado pelo conjunto de dentículos ou partículas calcificadas e o odontoma complexo consiste em uma massa de tecidos dentários aglomerados e distribuídos irregularmente ${ }^{6,9}$. Radiograficamente, o odontoma composto constitui um conjunto de estruturas radiopacas semelhante a dentículos de forma e tamanho variáveis. Já o odontoma complexo em uma massa calcificada, em forma esférica ou ovalada, ${ }^{6,9}$ Histologicamente, essas anomalias são constituídas de estruturas semelhantes às de um dente: matriz de esmalte, dentina, polpa e cemento ${ }^{9}$.

Cardoso et. al. ${ }^{6}$ afirmaram que as possíveis etiologias dos odontomas são infecção, pressão ou traumas que ao provocarem mutação em genes, alteram os mecanismos genético e controlador responsáveis pelo crescimento dentário. Também afirmam que o odontoma composto possui incidência em $67 \%$ dos casos, e o complexo $33 \%$.

Podem ser citados como tratamento para caninos impactados o transplante autógeno, a extração do canino decíduo, extração do canino impactado e, exposição cirúrgica e tracionamento ortodôntico. $\mathrm{O}$ tracionamento cirúrgico-ortodôntico pode ser realizado por meio da colagem de um acessório ortodôntico, laçada na cervical ou perfuração da coroa do dente impactado através do acesso cirúrgico $5,7,8$

Tracionamento é o procedimento utilizado quando se deseja aplicar uma força extrusiva ao dente impactado para que se consiga deslocá-lo em direção à cavidade bucal e posicioná-lo em condições estéticas e funcionais ${ }^{7}$.

No entanto, casos como esse requer alguns cuidados, pois a permanência do dente impactado ou o tracionamento em si podem afetar fatores biológicos e gerar algumas consequências locais ${ }^{10}$.

A reabsorção das raízes dos incisivos laterais e prémolares é uma das consequências devido à proximidade do folículo pericoronário que reveste a coroa do canino impactado. Isto ocorre porque mediadores químicos que estimulam a reabsorção presentes no folículo, como o EGF, ao longo do crescimento ósseo e erupção promovem a proximidade da coroa deste dente com a raiz do dente já irrompido, provocando a compressão dos vasos periodontais e morte dos cementoblastos ${ }^{7,10}$.

Outra consequência é a reabsorção cervical externa nos caninos tracionados, que está presente quando os "gaps" de dentina ficam expostos ao tecido conjuntivo após a remoção cirúrgica do folículo pericoronário da região cervical ou pelo trauma provocado pelo fio metálico durante o deslocamento, gerando um processo inflamatório constante. Expondo esses gaps, proteínas não registradas pelo organismo durante o processo de odontogênese e que ali ficam guardadas, são liberadas e em contato com as células de defesa do tecido conjuntivo serão consideradas como antígenos, resultando também em reabsorção ${ }^{11}$.

Consolaro et al. ${ }^{12}$ relatam ainda que anquilose e reabsorção por substituição são causadas pela força e velocidade da movimentação, e que a metamorfose cálcica da polpa e a necrose pulpar são caudadas pela luxação dentária induzida com dano do feixe vasculonervoso também são consequências do tracionamento ortodôntico.

\section{CASO CLÍNICO}

Paciente leucoderma de 15 anos, gênero masculino, acompanhado de seu responsável procurou a Clínica de Odontologia da Universidade Brasil, referenciado pelo ortodontista, com solicitação de procedimento cirúrgico e colagem de botão para tracionamento do dente 33 impactado.

$\mathrm{Na}$ radiografia panorâmica inicial trazida pelo paciente foi visualizado o canino permanente impactado, o canino decíduo ocupando seu espaço e uma pequena lesão com características de odontoma (Figura 1). Porém, no exame clínico, já não foi observado o dente decíduo, pois o mesmo havia sido removido em procedimento cirúrgico anterior por outro profissional.

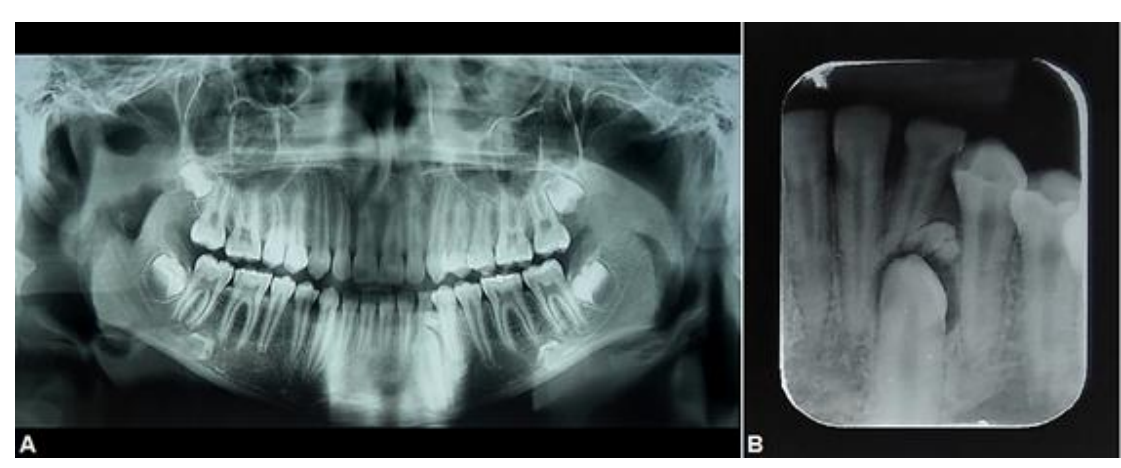

Figura 1: A. Radiografia panorâmica inicial. B. Radiografia periapical inicial: canino decíduo, odontoma e canino impactado.

Após anamnese completa do paciente e orientações, a cirurgia foi marcada. Dentre os tratamentos já citados, a colagem de botão ortodôntico foi escolhida pelas condições favoráveis do caso.

Para o procedimento cirúrgico, o paciente foi submetido à anestesia de bloqueio do nervo mentual complementado com terminal infiltrativa; incisão sulcular na vestibular e lingual do incisivo lateral e primeiro pré-molar e incisão supraperiosteal na região do canino; descolamento total para exposição óssea; octetomia da tábua óssea vestibular para exposição da coroa do canino e enucleção da lesão (Figura 2).
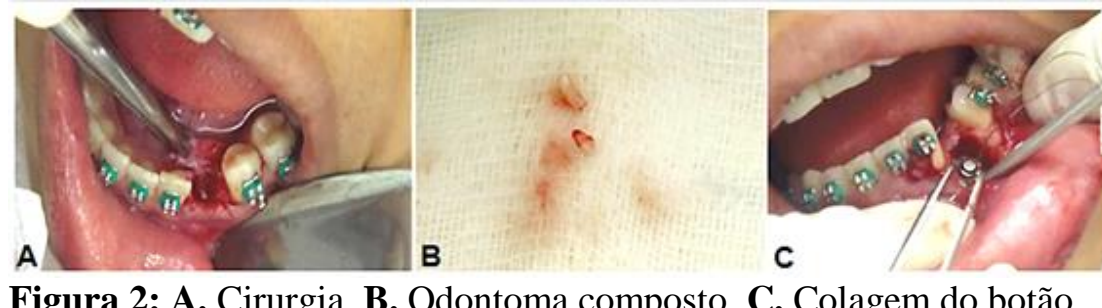

Figura 2: A. Cirurgia. B. Odontoma composto. C. Colagem do botão

A lesão composta por dois dentículos, confirmou a hipótese diagnóstica, odontoma (lesão sem teor maligno), razão pelo qual não julgado necessário o envio da amostra para análise histológica.

Após exposição da coroa, foram realizados os procedimentos a seguir: condicionamento com ácido fosfórico a $37 \%$ por 30 segundos em esmalte, lavagem e secagem, aplicação de adesivo e fotopolimerização, colagem de botão ortodôntico e fotopolimerização (Figura 2C), 
limpeza do meio com soro fisiológico e sutura.

Em pós-operatório de 7 dias, foi iniciado o tracionamento ortodôntico (Figura 3).

No retorno após cinco meses já foi possível visualizar a movimentação do canino em direção ao arco e o aparecimento do botão na mucosa. Oito meses após, a coroa já se apresentava visível. Com um ano de acompanhamento, quase toda a coroa estava irrompida, com o canino em giroversão. Nesta sessão o botão foi substituído por um bráquete (Figuras 4 e 5).

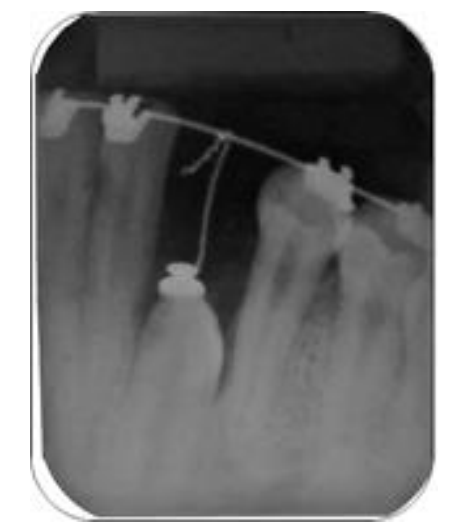

Figura 3: Radiografia: pós-operatório de 7 dias e início do tracionamento.

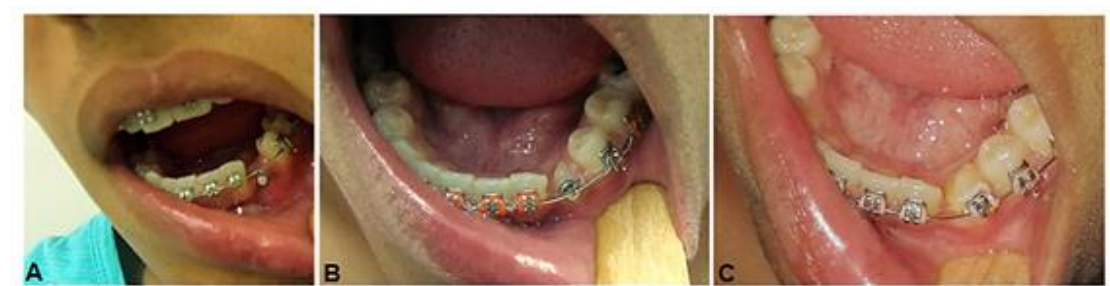

Figura 4: A. Acompanhamento de 5 meses (botão ortodôntico visualizado). B. Acompanhamento de 8 meses (visualização de parte da coroa). C. Acompanhamento de 12 meses (coroa quase totalmente exposta e cimentação do bráquete).

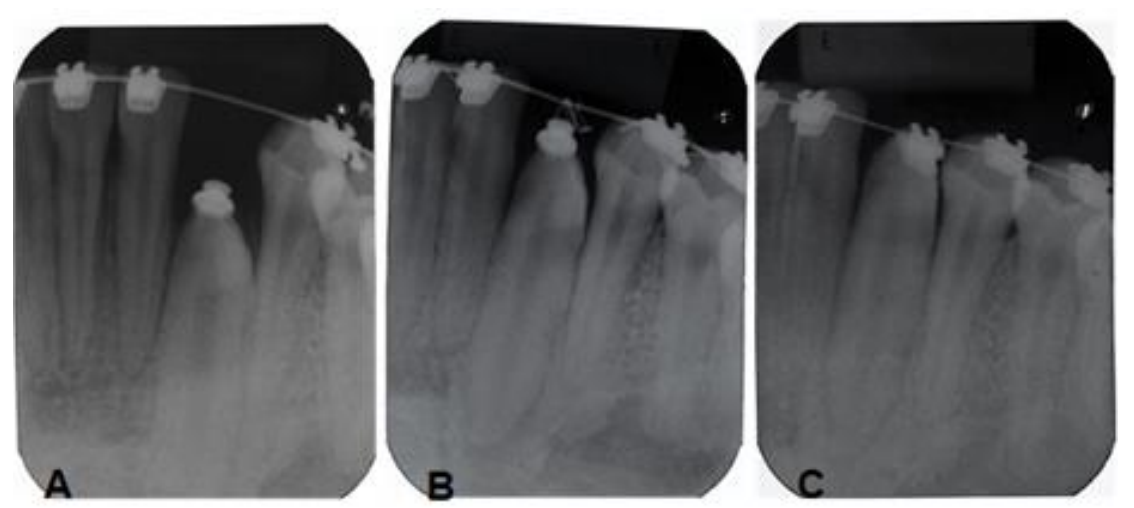

Figura 5: A. Radiografia Periapical após 5 meses. B. Radiografia Periapical após 8 meses. C. Radiografia Periapical após 12 meses.

Após dois anos de acompanhamento, clinicamente o dente encontrava-se em oclusão, faltando apenas ajustes no posicionamento dental para conclusão do tratamento ortodôntico. Radiograficamente se apresenta hígido, sem a possível reabsorção que poderia ser provocada pelo tracionamento (Figura 6).
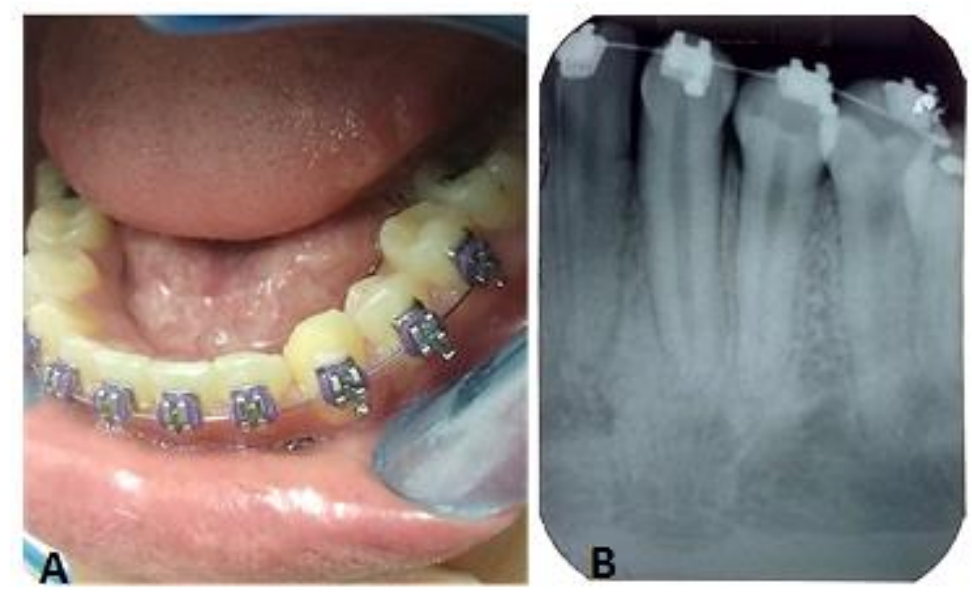

Figura 6: Dente em oclusão. A. Fotografia final. B. Radiografia final.

\section{DISCUSSÃO}

A impacção canina é a mais comum quando comparada aos demais dentes e ocorre por diversas causas, onde a escolha do tratamento dependerá de fatores como a idade do paciente, da posição do dente, do espaço disponível no arco e do estágio de desenvolvimento da dentição ${ }^{1,4,5,7,8}$.

Os tratamentos para caninos impactados vão desde a indução do seu deslocamento até a sua remoção ${ }^{5,7}$. O tipo tracionamento pode ser realizado de três maneiras: a primeira seria a laçada de um fio de aço na cervical do dente, técnica que está em desuso devido ao procedimento exigir extensa e traumática remoção óssea, e por provocar reabsorção radicular externa e anquilose; a segunda maneira, é através da perfuração da coroa e colocação de um pino de rosca, mas este procedimento nem sempre é realizado por conta da dificuldade de acesso, o que faz aumentar os riscos de danos pulpares ${ }^{4,8,13}$. Já a terceira opção, a mais utilizada, é a colagem de um acessório na coroa do canino (bráquete, gancho ou botão), por se tratar de uma técnica menos invasiva e de mais fácil execução. Também apresenta rápida cicatrização, menor desconforto pós-operatório e possibilita maior controle no movimento de tração. Porém sua desvantagem está em obter um campo operatório seco para a colagem adequada do acessório ${ }^{3,4,5,7,8}$

A impacção de canino inferior ocorre em menor frequência que o superior ${ }^{13,14}$ Trabalhos realizados por Britto et al. ${ }^{3}$, Marchioro et al. ${ }^{4}$ e Martins et al. ${ }^{13}$ descreveram a colagem de acessório ortodôntico em tais dentes e como esta técnica contribuiu positivamente ao tratamento.

É necessário um bom planejamento, além de correta execução da técnica em fase cirúrgica, que são passos primordiais para garantir o sucesso do tracionamento ortodôntico.

\section{CONCLUSÃO}

Os caninos são dentes que comumente sofrem impacção dental, sendo que o tracionamento ortodôntico é o tratamento de eleição em grande parte dos casos e depende de análise clínica e radiográfica detalhada, uma vez que requer técnica adequada e cuidados na sua execução. $\mathrm{O}$ caso aqui relatado teve diagnóstico precoce e prognóstico favorável, o que tornou possível o estabelecimento da estética e função.

\section{REFERÊNCIAS}

1. Almeida RR, Fuziy A, Almeida MR, Almeida-Pedrin RR, Henriques JFC, Bajo Insabralde CM. Abordagem da Impactação e/ou Irrupção Ectópica dos Caninos Permanentes: Considerações Gerais, Diagnóstico e Terapêutica. Rev dent press ortodon ortop facial. 2001; 6(1):93-116.

2. Hupp JR, Ellis III E, Tucker MR. Cirurgia oral e maxilofacial contemporânea. 5. ed. Rio de Janeiro: Elsevier; 2009.

3. Britto AM, Fraga CFF, Goursand D, Costa EM, Grossi E, Rocha Júnior JF. Impactação de caninos superiores e suas consequências: relato de caso clínico. J Bras Ortodon Ortop Facial. 2003; 8(48):453-9.

4. Marchioro EM, Hahn L. Método Alternativo de Tracionamento de Caninos Superiores Impactados. J Bras Ortodon Ortop Facial. 2001; 7(40):273-8.

5. Giglio FPM, Gurgel JA. Abordagem cirúrgicoortodôntica de dentes não irrompidos. Ortodontia SPO. 2010; 43(2):169-75. 
6. Cardoso LC, Miyahara GI, Magro Filho O, Garcia Júnior IR, Soubhia AMP. Odontoma combinado associado a dentes não irrompidos: Relato de casos clínicos. Rev Odontol Araçatuba 2003; 24(2):47-51.

7. Matsui RH, Kamitsuji IKN, Belini LPF, Chelotti A, Ortolani CLF, Faltin Júnior K. Caninos não irrompidos: alternativas de tratamento. Rev Inst Ciênc Saúde 2007; 25(1):75-83.

8. Simão TM, Neves MJG, Yamate EM, Crepaldi MV, Burger RC. Tratamento ortodôntico de caninos superiores impactados por palatino. Rev FAIPE 2012;2(1):29-40.

9. Neville BW, Damm DD, Allen CM, Bouquot JE. Patologia Oral \& Maxilofacial. 2. ed. Rio de Janeiro: Guanabara Koogan; 2004.

10. Consolaro A. Tracionamento ortodôntico: possíveis consequências nos caninos superiores e dentes adjacentes. Parte 1: reabsorção radicular nos incisivos laterais e pré-molares. Dental Press J Orthod 2010; 15(4):15-23.

11. Consolaro A. Tracionamento ortodôntico: possíveis consequências nos caninos superiores e dentes adjacentes. Parte 2: reabsorção cervical externa nos caninos tracionados. Dental Press J Orthod. 2010; 15(5): 23-30.

12. Consolaro A, Consolaro RB, Franchiscone LA. Tracionamento ortodôntico: possíveis consequências nos caninos superiores e dentes adjacentes. Parte 3: anquilose alveolodentária, reabsorção dentária por substituição, metamorfose cálcica da polpa e necrose pulpar asséptica. Dental Press J Orthod. 2010; 15(6):18-24.

13. Martins DR, Kawakami RY, Henriques JFC, Janson GRP. Impacção dentária: condutas clínicas apresentação de casos clínicos. Rev dent press ortodon ortop facial. 1998; 3(1):12-22.

14. Vasconcellos RJH, Oliveira DM, Melo Luz AC, Gonçalves RB. Ocorrência de dentes impactados. Rev cir traumatol buco-maxilo-fac. 2003; 3(1):1-5.

\section{CONFLITO DE INTERESSES}

Os autores declaram não haver conflitos de interesse.

\section{AUTOR PARA CORRESPONDÊNCIA}

Marlene Cabral Coimbra da Cruz

mcoimbracruz@gmail.com

Submetido em 02/04/2017

Aceito em 12/05/2017 